\title{
Large Gender Gap in Oral Hygiene Behavior and Its Impact on Gingival Health in Late Adolescence
}

\author{
Masanobu Abe ${ }^{1,2, *}$, Akihisa Mitani ${ }^{1}$, Kazuto Hoshi ${ }^{2}$ and Shintaro Yanagimoto ${ }^{1}(\mathbb{D}$ \\ 1 Division for Health Service Promotion, The University of Tokyo, Tokyo 113-0033, Japan; \\ mitania-int@h.u-tokyo.ac.jp (A.M.); yanagimoto@hc.u-tokyo.ac.jp (S.Y.) \\ 2 Department of Oral \& Maxillofacial Surgery, The University of Tokyo Hospital, Tokyo 113-8655, Japan; \\ hoshi-ora@h.u-tokyo.ac.jp \\ * Correspondence: abem-ora@h.u-tokyo.ac.jp; Tel.: +81-3-5800-8669; Fax: +81-3-5800-6832
}

Received: 15 May 2020; Accepted: 17 June 2020; Published: 18 June 2020

\begin{abstract}
Background: Epidemiologic studies provide broad-based evidence that males are at greater risk of severe periodontal diseases than females. Our recent findings further revealed that male gender was an independent risk factor for gingival bleeding in late adolescents in Japan. Gingival health status has been reported to be affected by oral hygiene behavior. However, gender difference in this regard has not yet been clarified. Methods: We conducted a retrospective review of mandatory medical questionnaires administered as part of a legally required freshman medical checkup between April 2017 and 2019 at the University of Tokyo. Results: Among a total of 9376 sets of responses, chosen subjects were 9098 students aged 17-19. For frequency of daily brushing, males brushed less frequently than females ( $p<0.001): 1$ time or less (male: $22.9 \%$, female: $11.2 \%)$, twice $(65.0 \%, 69.2 \%), 3$ times or more $(12.1 \%, 19.6 \%)$. For the duration of brushing each time, males brushed for a shorter period of time than females $(p=0.005)$ : $1 \mathrm{~min}$ or less (male: $17.2 \%$, female: $14.1 \%), 2-3 \mathrm{~min}(46.9 \%, 49.2 \%)$, 4 min or more (35.9\%, 36.7\%). (1) Male gender, (2) lower frequency of daily brushing and (3) shorter duration of brushing each time, were significantly associated with the presence of gingival bleeding $(p<0.001$ for all). Multivariate regression analysis showed that: (1) male gender (odds ratio 1.29, 95\% confidence interval 1.15-1.44); (2) frequency of daily brushing: 1 time or less (2.36, 2.02-2.76), twice (1.45, 1.27-1.67); and (3) brushing duration each time: $1 \mathrm{~min}$ or less $(1.57,1.39-1.78), 2-3 \mathrm{~min}$ $(1.26,1.14-1.39)$, were independent risk factors for gingival bleeding $(p<0.001$ for all). Conclusions: Males showed poorer oral hygiene behavior than females in late adolescents in Japan. Male gender was an independent risk factor for gingival bleeding, as well as poor oral hygiene behavior.
\end{abstract}

Keywords: oral hygiene behavior; sex; gender; periodontal disease; adolescence; adolescent

\section{Introduction}

Periodontal diseases (gingivitis and periodontitis) are highly prevalent, affecting up to $90 \%$ of the worldwide population [1]. They have been associated with various systemic diseases such as heart diseases, diabetes, respiratory diseases, rheumatism, metabolic syndrome, and so on [2-11]. Even in adolescents, the presence of gingival bleeding, one of the major symptoms of periodontal diseases, is suggested to be associated with several systemic diseases [12]. Therefore, the prevention and treatment of periodontal diseases have become increasingly important.

Large, cross-sectional, epidemiologic studies provide broad-based evidence of a sexual dimorphism in destructive periodontal diseases, reflecting a greater prevalence of periodontitis in males than females $[13,14]$. Our recent research adds a new insight to these findings; that is, male gender is an independent risk factor for gingival bleeding in late adolescents [12]. It has been reported that gingival health status is affected by oral hygiene behavior [15-20]. However, gender differences in oral 
hygiene behavior have not yet been clarified. The objective of this study was to investigate differences in oral hygiene behavior and its impact on gingival health in late adolescence by gender.

\section{Methods}

\subsection{Study Design and Population}

We performed a retrospective review of mandatory medical questionnaires administered as a part of a legally required freshman medical checkup between April 2017 and April 2019 at the University of Tokyo. Among a total of 9376 responses (7563 males, 1813 females, aged 17-59 years, mean age 18.4 years), all of the responses from students aged less than 20 years (9098 sets, 7316 males, 1782 females aged 17-19 years, mean age 18.3 years) were subjected to analyses.

\subsection{Questionnaire}

A self-administered, closed-ended questionnaire was distributed to all students (Supplementary File S1). To assess frequency of toothbrushing, the questionnaire asked: "How many times do you brush a day? Please choose one of the following options; 0 time, 1 time, 2 times, 3 times, 4 times or more". Another question addressed the duration of toothbrushing: "How long do you brush each time? Please choose one from the following options; less than $1 \mathrm{~min}, 1 \mathrm{~min}, 2-3 \mathrm{~min}, 4-5 \mathrm{~min}, 6 \mathrm{~min}$ or more". Gingival health status was assessed with the yes/no question: "Are you aware of gum bleeding when you brush?" [12]. After tallying each student's responses to the questionnaire, we investigated differences in the status of oral hygiene behavior between male and female adolescents.

\subsection{Statistical Analyses}

Statistical analysis was performed using a $\chi^{2}$ test and multivariate binomial logistic regression models. A value of $p<0.05$ (two-sided) was accepted as significant. All the analyses were conducted using the statistical software program SAS ver. 9.4 (SAS Institute Inc., Cary, NC, USA).

\subsection{Ethical Approval}

This retrospective study was approved by the research ethics committee of the University of Tokyo in 2018, approval no. 18-197 (currently, revised as no. 19-324), "Retrospective analyses of medical and health record information retained by the division for health service promotion, the University of Tokyo." We abided by all relevant laws, regulations and the university rules for privacy.

\section{Results}

\subsection{Gender Difference for the Frequency of Daily Brushing in Late Adolescents}

The data of 9098 students aged 17-19 were analyzed. Of these, data from 9072 students were valid for analysis of daily frequency of brushing. The respondents were categorized into three groups by their brushing frequency: " 1 time or less", "twice", " 3 times or more". In both males and females, brushing twice a day was the most common frequency. There was a greater number of males than females in the"1 time or less" group. The was a greater number of females than males in the other two groups (Figure 1, Table 1). The $\chi^{2}$ test revealed that males brush less frequently than females $(p<0.001)$. 


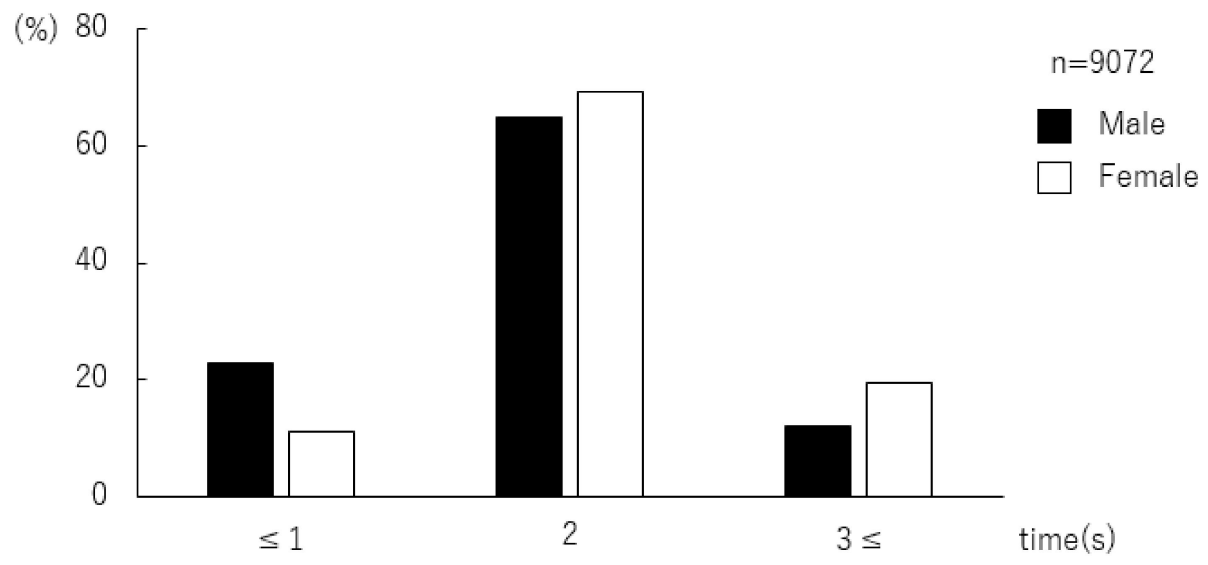

Figure 1. Distribution of adolescents by frequency of daily brushing. In both males and females, brushing "twice" a day was the most common frequency. There was a greater number of males than females in the group " 1 time or less" a day. There was a greater number of females than males in the other two groups, "twice" and "3 times or more" a day.

Table 1. Gender difference in daily toothbrushing frequency $\left(\chi^{2}\right.$ test).

\begin{tabular}{|c|c|c|c|c|}
\hline Frequency of Daily Brushing & All $(n=9072)$ & Male $(n=7294)$ & Female $(n=1778)$ & $n$ \\
\hline Time (s) & $n(\%)$ & $n(\%)$ & $n(\%)$ & 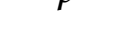 \\
\hline$\leq 1$ & $1868(20.6)$ & $1669(22.9)$ & $199(11.2)$ & $<0.001 *$ \\
\hline 2 & $5971(65.8)$ & $4741(65.0)$ & $1230(69.2)$ & \\
\hline $3 \leq$ & $1233(13.6)$ & $884(12.1)$ & $349(19.6)$ & \\
\hline
\end{tabular}

\subsection{Gender Difference for the Duration of Brushing Each Time in Late Adolescents}

Of data from 9098 students aged 17-19, those from 9070 students were valid for the analysis of duration of brushing each time. The respondents were categorized into three groups by the duration of brushing each time: " $1 \mathrm{~min}$ or less", "2-3 min", and " 4 min or more". Both in males and females, "2-3 min" was the most common brushing duration. There was a greater number of males than females in the group of " $1 \mathrm{~min}$ or less". There was a greater number of females than males in the other two groups (Figure 2, Table 2). The $\chi^{2}$ test revealed that males brush for shorter periods of time than females $(p=0.005)$.

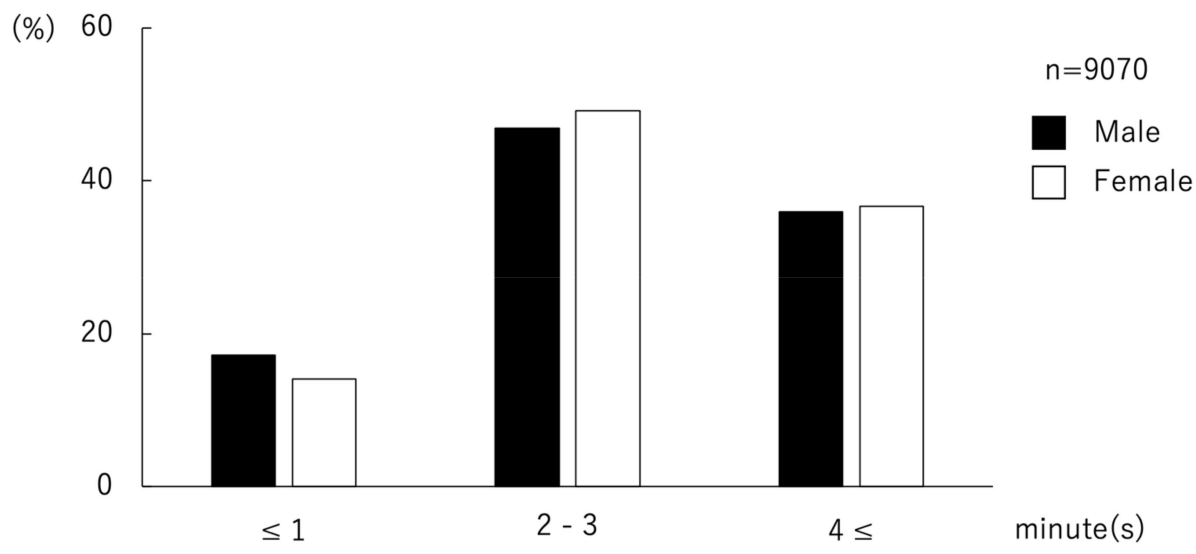

Figure 2. Distribution of adolescents for duration of toothbrushing. In both males and females, " 2 or $3 \mathrm{~min}$ " was the most common duration of brushing each time. There was a greater number of males than females in the group " $1 \mathrm{~min}$ or less". The was a greater number of females than males in the other two groups, " 2 or $3 \mathrm{~min}$ " and " 4 min or more". 
Table 2. Gender difference in toothbrushing duration $\left(\chi^{2}\right.$ test).

\begin{tabular}{|c|c|c|c|c|}
\hline Duration of Brushing & All $(n=9070)$ & Male $(n=7293)$ & Female $(n=1777)$ & $p$ \\
\hline $\min$ & $n(\%)$ & $n(\%)$ & $n(\%)$ & $r$ \\
\hline$\leq 1$ & 1508 (16.6) & $1258(17.2)$ & $250(14.1)$ & $0.005 *$ \\
\hline $2-3$ & $4291(47.3)$ & 3417 (46.9) & $874(49.2)$ & \\
\hline $4 \leq$ & $3271(36.1)$ & $2618(35.9)$ & $653(36.7)$ & \\
\hline
\end{tabular}

\subsection{The Association of Gingival Bleeding with Gender and Oral Hygiene Behavior}

The associations of gingival bleeding with gender and oral hygiene behavior (frequency of daily brushing and brushing duration) were analyzed by $\chi^{2}$ tests. The results revealed that male gender, lower frequency of daily brushing and shorter brushing duration were significantly associated with the presence of gingival bleeding $(p<0.001$ for all, Table 3$)$. A multivariate analysis was conducted for the complete series of respondents using a binomial logistic regression model with gingival bleeding as the objective variable (gingival bleeding as an event), and using male gender, frequency of daily brushing ( $\leq 1$ time, 2 times), and brushing duration ( $\leq 1 \mathrm{~min}, 2-3 \mathrm{~min}$ ) as explanatory variables. The results showed significant rates for the following factors: (1) male gender (odds ratio (OR) 1.29, 95\% confidence interval (CI): 1.15-1.44, $p<0.001)$, (2) frequency of daily brushing: $\leq 1$ time (OR $2.36,95 \% \mathrm{CI}$ : 2.02-2.76, $p<0.001$ ), 2 times (OR 1.45, 95\% CI: 1.27-1.67, $p<0.001$ ) and (3) brushing duration: $\leq 1 \mathrm{~min}$ (OR 1.57, 95\% CI: 1.39-1.78, $p<0.001$ ), 2-3 min (OR 1.26, 95\% CI: 1.14-1.39, $p<0.001$ ). Male gender, frequency of daily brushing ( $\leq 1$ time, 2 times), and duration of brushing each time ( $\leq 1 \mathrm{~min}, 2-3 \mathrm{~min}$ ), were independent risk factors for gingival bleeding (Table 4).

Table 3. The association of gingival bleeding with gender and oral hygiene behavior $\left(\chi^{2}\right.$ test).

\begin{tabular}{|c|c|c|c|c|}
\hline & \multirow{3}{*}{$n$} & \multicolumn{2}{|c|}{ Gingival Bleeding } & \multirow{3}{*}{$p$} \\
\hline & & Presence & Absence & \\
\hline & & $n(\%)$ & $n(\%)$ & \\
\hline All & 9098 & $3321(36.5)$ & $5777(63.5)$ & \\
\hline \multicolumn{5}{|l|}{ Gender } \\
\hline Male & 7316 & $2780(38.0)$ & $4536(62.0)$ & $<0.001 *$ \\
\hline Female & 1782 & $541(30.4)$ & $1241(69.6)$ & \\
\hline \multicolumn{5}{|c|}{ Frequency of daily brushing (times) } \\
\hline$\leq 1$ & 1868 & $881(47.2)$ & $987(52.8)$ & $<0.001 *$ \\
\hline 2 & 5971 & $2108(35.3)$ & $3863(64.7)$ & \\
\hline $3 \leq$ & 1233 & $331(26.8)$ & $902(73.2)$ & \\
\hline \multicolumn{5}{|c|}{ Duration of brushing (min) } \\
\hline$\leq 1$ & 1508 & $653(43.3)$ & $855(56.7)$ & $<0.001 *$ \\
\hline $2-3$ & 4291 & $1593(37.1)$ & $2698(62.9)$ & \\
\hline $4 \leq$ & 3271 & $1073(32.8)$ & $2198(67.2)$ & \\
\hline
\end{tabular}


Table 4. Multivariate regression analysis for the association of gingival bleeding with gender and oral hygiene behavior.

\begin{tabular}{ccc}
\hline & Odds Ratio (95\% CI) & $p$ \\
\hline $\begin{array}{c}\text { Gender } \\
\text { Male }\end{array}$ & $1.29(1.15-1.44)$ & $<0.001^{*}$ \\
Female & 1 & - \\
\hline Frequency of daily brushing (times) & $2.36(2.02-2.76)$ & $<0.001^{*}$ \\
$\leq 1$ & $1.45(1.27-1.67)$ & $<0.001^{*}$ \\
2 & 1 & - \\
$3 \leq$ & & $<0.001^{*}$ \\
\hline Duration of brushing (min) & $1.57(1.39-1.78)$ & $<0.001^{*}$ \\
$\leq 1$ & $1.26(1.14-1.39)$ & - \\
$2-3$ & 1 &
\end{tabular}

CI: confidence interval, ${ }^{*}:<0.05$.

\section{Discussion}

Periodontal diseases, gingivitis and periodontitis are the most common oral disorders affecting the supporting structures of teeth and are partially responsible for tooth loss. They are also associated with various systemic diseases [2-12,21,22]. Thus, prevention and treatment of periodontal diseases have recently become a public health focus [23-25].

Lower frequency of daily brushing and shorter brushing duration have been closely associated with gingival bleeding. In multivariate analysis, they were found to be independent risk factors for gingival bleeding. There have been relatively fewer studies evaluating the association between oral hygiene behaviors and periodontal diseases. However, a recent meta-analysis indicated that infrequent tooth brushing was associated with severe forms of periodontal disease [19]. In another multivariate analysis, Lertpimonchai et al. revealed that poor oral hygiene behavior increased the risk of periodontitis [20]. In this study, we increased the evidence level of the association between oral hygiene behavior and periodontal disease. Periodontal diseases occur by a complex interplay of various etiological factors. Particularly, a history of medication can cause gingival bleeding. Thus, we would like to address this issue in our future study.

In the current study, males displayed poorer oral hygiene behavior than females. We found similar results that revealed gender difference with regard to daily toothbrushing frequency in our previous study involving university students [18]. Outside Japan, Olczak-Kowalczyk et al. investigated oral hygiene status in Polish adolescents and found that prevalence of gingival bleeding was higher in males [16]. Almas et al. revealed that female university students had better oral hygiene practices compared to male students in Saudi Arabia [26]. Even in adults, significant gender difference for the frequency of daily brushing has been reported [27]. Thus, the significant gender difference in oral hygiene behavior observed in this study might point to a common problem worldwide regardless of age. In a future study, we would like to address other parameters such as education level, economic status, status of usage of other oral hygiene devices such as dental floss, electric toothbrush, interdental brush, mouthwash and tongue cleaner in late adolescents.

Large epidemiologic studies provide evidence that severe periodontal disease has a documented higher prevalence in males compared to females $[13,14]$. In this study, male gender was an independent risk factor for gingival bleeding as well as poorer oral hygiene behavior in late adolescents. The result suggested that the gender gap of morbidity for severe periodontal diseases, which are generally observed in adults, had already begun in late adolescence. Sexual dimorphisms sometimes result from genetic and epigenetic differences in gene regulation [28]. Differential gene expression in sex steroid-responsive genes were reported to contribute to a sexual dimorphism in susceptibility to severe periodontal disease [14]. 
Systemic health condition is affected by oral hygiene level. For example, improved oral hygiene behavior is associated with decreased risk of atrial fibrillation and heart failure [29]. Periodontal therapy provides good systemic effects in patients with type 2 diabetes [22]. A meta-analysis showed that the risk of periodontitis could be reduced by regular toothbrushing [20]. Thus, increased awareness of oral health and hygiene behavior in young people, particularly males, would decrease not only the future severity of periodontal diseases but also systemic diseases that are affected by gingival health status in the elderly.

In summary, it was found that males showed poorer oral hygiene behavior than females in late adolescents in Japan and, furthermore, male gender was an independent risk factor for gingival bleeding as well as poor oral hygiene behavior. However, there was a disparity in the recruited number of male and female subjects in the present study. Thus, additional studies are needed to validate these findings by equal recruitment of male and female subjects.

\section{Conclusions}

Males showed poorer oral hygiene behavior than females in late adolescents in Japan. Male gender was an independent risk factor for gingival bleeding as well as poor oral hygiene behavior. Further research is needed to validate these findings.

Supplementary Materials: The following are available online at http://www.mdpi.com/1660-4601/17/12/4394/s1: self-administered, closed-ended questionnaire.

Author Contributions: M.A. conceived and designed this study. S.Y. contributed to data collection. M.A. and A.M. conducted data analysis. M.A., A.M. and S.Y. contributed to interpretation of the results. M.A. wrote the manuscript, which K.H. and S.Y. critically reviewed. All authors have read and approved the final version of the manuscript and agree to be accountable for all aspects of the work in ensuring that questions related to the accuracy or integrity of any part are appropriately investigated and resolved.

Funding: This research received no external funding.

Conflicts of Interest: The authors declare that they have no competing interests.

Declarations: This study was approved by the Research Ethics Committee of the University of Tokyo in 2018, approval no. 18-197 (currently, revised as no. 19-324), "Retrospective analyses of medical and health record information retained by the division for health service promotion, the University of Tokyo." We abided by all relevant laws, regulations and the University rules for privacy. Our privacy policy was posted on the website (http://www.hc.u-tokyo.ac.jp/). In accordance with the conditions stated in the ethics approval, we also posted a notice on the website of the department announcing the privacy policy and providing instructions for those who chose to opt out (https://www.lifescience.mext.go.jp/files/pdf/n2181_01.pdf).

\section{References}

1. Pihlstrom, B.L.; Michalowicz, B.S.; Johnson, N.W. Periodontal diseases. Lancet 2005, 366, $1809-1820$. [CrossRef]

2. Moreillon, P.; Que, Y.A. Infective endocarditis. Lancet 2004, 363, 139-149. [CrossRef]

3. Kaur, S.; White, S.; Bartold, P.M. Periodontal disease and rheumatoid arthritis: A systematic review. J. Dent. Res. 2013, 92, 399-408. [CrossRef]

4. Scannapieco, F.A.; Cantos, A. Oral inflammation and infection, and chronic medical diseases: Implications for the elderly. Periodontol. 2000 2016, 72, 153-175. [CrossRef] [PubMed]

5. Lamster, I.B.; Pagan, M. Periodontal disease and the metabolic syndrome. Int. Dent. J. 2016, 67, 67-77. [CrossRef]

6. Han, Y.W.; Wang, X. Mobile microbiome: Oral bacteria in extra-oral infections and inflammation. J. Dent. Res. 2013, 92, 485-491. [CrossRef]

7. Abe, M.; Abe, T.; Mogi, R.; Kamimoto, H.; Hatano, N.; Taniguchi, A.; Saijo, H.; Hoshi, K.; Takato, T. Cervical necrotizing fasciitis of odontogenic origin in a healthy young patient without pre-systemic disorders. J. Oral Maxillofac. Surg. Med. Pathol. 2017, 29, 341-344. [CrossRef]

8. Abe, M.; Mori, Y.; Inaki, R.; Ohata, Y.; Abe, T.; Saijo, H.; Ohkubo, K.; Hoshi, K.; Takato, T. A Case of Odontogenic Infection by Streptococcus constellatus Leading to Systemic Infection in a Cogan's Syndrome Patient. Case Rep. Dent. 2014, 2014, 793174. 
9. Abe, M.; Mori, Y.; Saijo, H.; Hoshi, K.; Ohkubo, K.; Ono, T.; Takato, T. The efficacy of dental therapy for an adult case of Henoch-Schönlein Purpura. Oral Sci. Int. 2012, 9, 59-62. [CrossRef]

10. Inagaki, Y.; Abe, M.; Inaki, R.; Zong, L.; Suenaga, H.; Abe, T.; Hoshi, K. A Case of Systemic Infection Caused by Streptococcus pyogenes Oral Infection in an Edentulous Patient. Diseases 2017, 5, 17. [CrossRef]

11. Inaki, R.; Igarashi, M.; Abe, M.; Saijo, H.; Hoshi, K.; Takato, T. A case of infective endocarditis by Streptococcus mutans bacteremia induced by asymptomatic chronic dental caries in a wisdom tooth. Oral Sci. Jpn. 2014, 9, 95-96.

12. Abe, M.; Mitani, A.; Yao, A.; Takeshima, H.; Zong, L.; Hoshi, K.; Yanagimoto, S. Close Associations of Gum Bleeding with Systemic Diseases in Late Adolescence. Int. J. Environ. Res. Public Health. 2020, 4290. [CrossRef]

13. Shiau, H.J.; Reynolds, M.A. Sex differences in destructive periodontal disease: A systematic review. J. Periodontol. 2010, 81, 1379-1389. [CrossRef]

14. Shiau, H.J.; Reynolds, M.A. Sex differences in destructive periodontal disease: Exploring the biologic basis. J. Periodontol. 2010, 81, 1505-1517. [CrossRef] [PubMed]

15. Pawlaczyk-Kamienska, T.; Torlinska-Walkowiak, N.; Borysewicz-Lewicka, M. The relationship between oral hygiene level and gingivitis in children. Adv. Clin. Exp. Med. Off. Organ. Wroc. Med. Univ. 2018, 27, 1397-1401. [CrossRef]

16. Olczak-Kowalczyk, D.; Gozdowski, D.; Kaczmarek, U. Oral Health in Polish Fifteen-year-old Adolescents. Oral Health Prev. Dent. 2019, 17, 139-146.

17. Mizutani, S.; Ekuni, D.; Furuta, M.; Tomofuji, T.; Irie, K.; Azuma, T.; Kojima, A.; Nagase, J.; Iwasaki, Y.; Morita, M. Effects of self-efficacy on oral health behaviours and gingival health in university students aged 18- or 19-years-old. J. Clin. Periodontol. 2012, 39, 844-849. [CrossRef]

18. Hikiji, H.; Koshikiya, N.; Fujihara, H.; Hatano, N.; Matsuzaki, M.; Matsuzaki, A.; Ohki, M.; Susami, T.; Takato, T.; Toyo-oka, T. Changes in the awareness of oral health among new students newly enrolled at the University of Tokyo over the past 15 years. Int. J. Dent. Hyg. 2005, 3, 137-144. [CrossRef]

19. Zimmermann, H.; Zimmermann, N.; Hagenfeld, D.; Veile, A.; Kim, T.S.; Becher, H. Is frequency of tooth brushing a risk factor for periodontitis? A systematic review and meta-analysis. Community Dent. Oral Epidemiol. 2015, 43, 116-127. [CrossRef]

20. Lertpimonchai, A.; Rattanasiri, S.; Arj-Ong Vallibhakara, S.; Attia, J.; Thakkinstian, A. The association between oral hygiene and periodontitis: A systematic review and meta-analysis. Int. Dent. J. 2017, 67, 332-343. [CrossRef]

21. Si, Y.; Fan, H.; Song, Y.; Zhou, X.; Zhang, J.; Wang, Z. Association between periodontitis and chronic obstructive pulmonary disease in a Chinese population. J. Periodontol. 2012, 83, 1288-1296. [CrossRef] [PubMed]

22. D'Aiuto, F.; Gkranias, N.; Bhowruth, D.; Khan, T.; Orlandi, M.; Suvan, J.; Masi, S.; Tsakos, G.; Hurel, S.; Hingorani, A.D.; et al. Systemic effects of periodontitis treatment in patients with type 2 diabetes: A 12 month, single-centre, investigator-masked, randomised trial. Lancet Diabetes Endocrinol. 2018, 6, 954-965. [CrossRef]

23. Peres, M.A.; Macpherson, L.M.D.; Weyant, R.J.; Daly, B.; Venturelli, R.; Mathur, M.R.; Listl, S.; Celeste, R.K.; Guarnizo-Herreno, C.C.; Kearns, C.; et al. Oral diseases: A global public health challenge. Lancet 2019, 394, 249-260. [CrossRef]

24. Watt, R.G.; Daly, B.; Allison, P.; Macpherson, L.M.D.; Venturelli, R.; Listl, S.; Weyant, R.J.; Mathur, M.R.; Guarnizo-Herreno, C.C.; Celeste, R.K.; et al. Ending the neglect of global oral health: Time for radical action. Lancet 2019, 394, 261-272. [CrossRef]

25. Dubar, M.; Delatre, V.; Moutier, C.; Sy, K.; Agossa, K. Awareness and practices of general practitioners towards the oral-systemic disease relationship: A regionwide survey in France. J. Eval. Clin. Pract. in press. [CrossRef] [PubMed]

26. Almas, K.; Al-Hawish, A.; Al-Khamis, W. Oral hygiene practices, smoking habit, and self-perceived oral malodor among dental students. J. Contemp Dent. Pr. 2003, 4, 77-90. [CrossRef]

27. Górska, R.; Górski, B. Self-reported Oral Status and Habits Related to Oral Care in Adult Poles: A Questionnaire Study. Dent. Med. Probl. 2018, 55, 313-320. [CrossRef] [PubMed] 
28. Abe, M.; Tsai, S.Y.; Jin, S.G.; Pfeifer, G.P.; Szabo, P.E. Sex-specific dynamics of global chromatin changes in fetal mouse germ cells. PLoS ONE 2011, 6, e23848. [CrossRef]

29. Chang, Y.; Woo, H.G.; Park, J.; Lee, J.S.; Song, T.J. Improved oral hygiene care is associated with decreased risk of occurrence for atrial fibrillation and heart failure: A nationwide population-based cohort study. Eur. J. Prev. Cardiol. in press. [CrossRef]

(C) (1)

(C) 2020 by the authors. Licensee MDPI, Basel, Switzerland. This article is an open access article distributed under the terms and conditions of the Creative Commons Attribution (CC BY) license (http://creativecommons.org/licenses/by/4.0/). 